Empire Marketing Board, special investigations on the distribution, breeding areas, migration routes, ecology, and bionomics of locusts in tropical Africa and Asia. An appeal was made by the British Government to the governments of other countries interested in the locust problem to help in these studies, and the Italian Government came forward with a suggestion to call together a meeting of experts to discuss the ways and means for a unified attack of the problem. The meet ing, in which British, Italian, and French experts participated, took place in September last in Rome, and its resolutions, which have just been published, constitute the first step towards an effort to solve the locust problem on an intemational scale. The meeting expressed a definite opinion that the best and most economical method of preventing the ravages of locusts consists in the discovery of permanent breeding areas, and in the study of ecological conditions which lead to the outbreaks and invasions of cultivated areas.

SINCE in their migrations locusts do not respect political boundaries, the necessity of centralising all research on locusts in one institution was stressed at the meeting in Rome, and it was recommended to all the governments concerned that the Imperial Institute of Entomology should be recognised as the international centre of locust investigations. This decision has since been accepted by the Italian and French authorities. All current information on the appear. ances, breeding, and migrations of locusts are to be submitted periodically to the Institute, which will co-ordinate the data for the whole area of distribution of each locust species and study them in order to throw light on the factors governing the outbreaks and the main lines of migrations. All governments not represented at the Rome meeting, but interested in the locust problem, will be invited to co-operate with the central Institute; and annual meetings of experts will be arranged to discuss the progress made in each country in the study of locusts, and the programmes of future work. The next meeting of this kind is planned to take place in Paris at the time of the Fifth International Entomological Congress in July.

\section{The Lapel Microphone}

AT public meetings and at lectures, the microphone and loud speaker is often a great boon to both the speaker, who speaks practically in his natural voice, and to the audience, who hear him clearly. There are some, however, who forget that they are addressing a stationary microphone and move about freely, with the result that sometimes they can scarcely be heard. To get over this difficulty, the Bell Telephone Company has invented the lapel microphone, a description of which is given in its Record for January. The microphone is only about an inch in diameter and weighs one and one-half ounces. A thirty-foot length of flexible cord provides the connexion to the amplifier of the public address system. The diaphragm is made of thin aluminium in the shape of a cone of sufficient stiffness to cause it to vibrate as a unit throughout the required frequency range. A rubber covering for the microphone eliminates the disturbing noise which would otherwise result from rubbing against the speaker's clothing, or would be picked up through the clip which is provided for attaching it to the clothing. The best place to attach the clip is to the lapel of the speaker's coat. This device has been used very successfully in large auditoriums in America. It should prove useful to speakers who depend on gestures for effective delivery or who need to turn to explain lantern slides or use a blackboard.

\section{Publications of the American Physical Society}

COMMENCING with the first issue for January of this year, the Physical Review is publishing the titles of papers on physies that are appearing in a number of other journals. The value of this innovation is enhanced by the fact that arrangements have been concluded whereby many of these will furnish advance proofs of their tables of contents. The first list is fairly comprehensive, although one notices the omission of the Proceedings of the Cambridge Philosophical Society, and of a few others, which may, however, be rectified later. The American journals include, amongst others, the Journals of the Acoustical and Optical Societies, the Journal of Rheology, the Review of Scientific Instruments and Physics. This is the fifth comparatively recent change in the publications of the American Physical Society and follows the appearance of the Physical Review twice every month in place of twelve times in a year, the addition of a section in this for "Letters to the Editor", and the publication of the two new periodicals Physics and Reviews of Modern Physics.

\section{Comité International d'Histoire des Sciences}

THE fourth annual meeting of this Society, the second international congress of which, it will be remembered, was held in London last July, is to take place in Paris on May 13-16. The Council of the Society is convinced that one of the most important tasks confronting the historian of science is to study the development under Arabic influence during the period of its dominance, say from the date of the Mussulman conquest until the beginning of the sixteenth century. To promote and organise this study, the scientific sessions, as distinct from the business sessions which are confined to members, will be devoted exclusively to papers and discussions on Arabic science. In these sessions all those who are interested, members or not, are invited to take part and to submit papers. There will be five sessions, devoted to mathematics, alchemy, astronomy and physics, geography and cartography, and medicine respectively. The meeting will take place at the headquarters of the Society, Hôtel de Nevers, 12 rue Colbert, Paris, $2 \Theta$; the permanent secretary, M. Aldo Mieli, will be pleased to furnish a programme and further details.

\section{Progress of Agricultural Research}

THE sixth of the series of annual summaries of scientific and economic research work in agriculture has been published by the Royal Agricultural Society of England, entitled "Agricultural Research in 1930". The survey which the volume contains is not limited to work done in Great Britain, but includes reference to the activities of experimental stations in all parts of the world, in so far as they have a bearing upon the 